\title{
JORNALISMO CULTURAL BRASILEIRO: aspectos e tendências
}

\author{
Brazilian altural journalism: aspects and trends
}

\begin{abstract}
Francisco de Assis
Mestrando em Comunicação Social e especialista em Jornalismo Cultural pela Universidade Metodista de São Paulo (UMESP), Jornalista formado pela Universidade de Taubaté (Unitau), pesquisador do Núcleo de Pesquisa e Estudos em Comunicação (Nupec) na mesma instituição, Taubaté, SP - Brasil, e-mail: francisco-nupec@ uol.com.br
\end{abstract}

\begin{abstract}
Resumo
O artigo discute os aspectos que norteiam a produção do jornalismo cultural no Brasil e aponta suas principais tendências. Adota a pesquisa bibliográfica como recurso metodológico, identificando a natureza dessa especialidade jornalística elevantando questões pertinentes a ela. Para isso, realizou-se um levantamento das principais obras sobre 0 assunto - entre livros, artigos e demais trabalhos acadêmicos - existentes na literatura comunicacional brasileira. A discussão proposta se apoia em cinco vertentes consideradas fundamentais para a discussão sobre a prática jornalística na área cultural: os possíveis limites entre cultura e entretenimento; a produção de variedades; a influência da propaganda e da concorrência; o papel da crítica a respeito dos bens simbólicos; e o preparo do jornalista. Como resultado, o texto evidencia a organização do jornalismo cultural na imprensa brasileira e reforça a importância da qualidade desse tipo de produto midiático.
\end{abstract}

Palavras-chave: Jornalismo cultural; Produção jornalística; Imprensa brasileira; Q ualidade do jornalismo.

\begin{abstract}
The article discusses the aspects which guide the production of cultural journalism in Brazil and points out to its main tendencies. It adopts bibliographical research as the methodological resource in order to identify the nature of this journalistic specialty and raise issues related to it. For this, a survey that located the main papers on the topic was carried out-among books, articles and other academic papers - existing in the Brazilian communicational literature. The proposed discussion is based basically on five particularities considered as fundamental to the discussion about the journalistic practice directed to the cultural area; the possible limits between culture and entertainment; the production of features; the influence of advertisement and of competitors, the critics' role about the symbolic goods and the journalists' background. As a concrete result, the text evidences the way cultural journalism is organized in the Brazilian press and reinforces the importance of the quality of this kind of media product.
\end{abstract}

Keywords: Cultural journalism; Journalistic production; Brazilian press; Quality of journalism. 


\section{INTRODUÇÃO}

A produção jornalística na área da cultura, especialmente no Brasil, é assunto de constantes discussões no meio acadêmico e no mercado midiático. Nesse debate, como é de se supor, há sempre os que reconhecem o valor dos produtos dessanatureza eseinteressam em pensaralternativas para melhorar sua qualidade, como também há os queclassificam essa modalidade do jornalismo como algo sem muita importância.

De todo modo, é certo que o jornalismo cultural existe em virtude de uma demanda social. A necessidade que as pessoas têm de saber o que ocorre pelo mundo, para que possam constituir elos com grupos, comunidades e com o próprio ambiente em que vivem (MARQUES DE MELO , 1991), não se resume à apreciação de notícias sobre política, economia, saúde, polícia e demais pautas tão bem vistas pelo mercado da comunicação; essesindivíduos também carecem de informações sobre artes, espetáculos, livros e tantos outros assuntos que possam ser úteis em momentos de descanso e lazer.

Também não se pode negar que a prática dessa especialidade é algo que chama a atenção de alguns jornalistas pela possibilidade de "unir o útil ao agradável". Ou seja, é uma forma de exercer a profissão, ao mesmo tempo em que se pode visitar exposições, ouvirCD s, assistiraDVD s, ir ao cinema, ler livros, entrevistar artistas e celebridades e, no final, receber uma remuneração (PIZA, 2003). Sem sombra de dúvidas, é um trabalho que aparenta ser atraente e prazeroso; mas também é um ofício que despertacríticas, secomparado àrotinadeprofissionais de outras editorias que passam horas da jornada em delegacias, na confusão das ruas da cidade ou, até mesmo, acompanhando agenda de políticos.

Este artigo procura levantar, pelo menos, cinco temas pertinentes para 0 atual momento experimentado pelo jornalismo cultural: a dicotomia cultura e entretenimento; o lugar ocupado pelas variedades nos "segundos cadernos" dos jornais diários; os vilões denominados concorrência e propaganda, que colocam à prova a credibilidade e 0 próprio conteúdo publicado nesses espaços editoriais; o espaço da crítica; e, por fim, o preparo profissional.
A reflexão se apoia na pesquisa bibliográfica, com a reunião de obras específicas sobre 0 assunto e de outros textos de referência. É importante dizer que a abordagem não pretende dar conta de todo o fenômeno, mas busca sinalizar seus principais aspectos e suas principais tendências.

\section{Cultura versus entretenimento}

Bem se sabe que os cadernos (ou suplementos) culturais surgiram com o propósito de reunir, num mesmo espaço, textos queversassem sobre assuntos relacionados às artes e a outras pautas que a mídia aponta como cultura. ${ }^{1} \mathrm{E}$ tal editoria fora pensada não apenas para se destinar à informação, mas também para ser ocupada pela crítica acerca desses assuntos, como forma de enaltecer os sentidos que as manifestações artísticoculturais podem despertar no ser humano. No entanto, com o passar do tempo, esse tipo de jornalismo tomou novas formas.

Alguns estudiosos da área (MEDINA, 1992; NUNES, 2003) consideram a década de 1970 como marco das mudanças ocorridas no jornalismo cultural. Nessa época, a mídia impressa passou a reservar espaços diferenciados - muitas vezes, cadernos individuais - para pautas dessa natureza e, também, começou a dar destaque para assuntos populares, deformanão muito consistente.

Essa, por assim dizer, "popularização" do jornalismo cultural - que transformou os "segundos cadernos" dos jornais diários e as revistas semanais e especializadas em produtos prioritariamente pautados por agendamento - acabou por banalizar sua produção, desencadeando sérias discussões sobre sua legitimidade. 0 jornalista José Geraldo Couto (COUTO, 1996, p. 129) é um dos que veem tal modificação como presságio para o momento de crise ao qual se submete a imprensa brasileira e cuja origem advém de uma série de problemas: excesso de espaço destinado a roteiros de programação cultural, em detrimento de reportagens; substituição da crítica pela resenha; coberturas realizadas de modo superficial, com destaque para produtos massivos; relação comprometedora da redação com

\footnotetext{
${ }^{1}$ Falar de cultura não é simples. 0 antropólogo CANCLINI, N. G. D iferentes, desiguais e desconectados. Rio de Janeiro: E ditora UFRJ, 2006, por exemplo, descobriu que existem mais de 300 usos distintos para o termo (e ainda considera o montante baixo). Por isso, o conceito de cultura utilizado neste texto é o que os meios de comunicação definem como cultura, que, grosso modo, seriam as sete grandes artes (pintura, escultura, dança, teatro, música, poesia e cinema), os shows, os patrimônios históricos e outras manifestações semelhantes.
} 
departamentos de marketing de empresas que promovem eventos de cultura; e falta de seriedade no exercício da função jornalística na área cultural. Para o autor, "aacelerada transformação do mercado de produtos culturais e a não menos rápida modernização dos jornais" são dois grandes fatores responsáveis por essas dificuldades, uma vez que "no novo contexto criado a partir desse conjunto de mudanças, o jornalismo cultural ainda não encontrou o seu espaço e a sua voz."

A defesa por um jornalismo cultural mais comprometido é abraçada por muitos e há um bom tempo. Já no início da década de 1990, acadêmicos elaboraram dois programas de discussões que apresentassem caminhos para se pensar nos reflexos provocados pela subdivisão da editoria e pelas demandas do mercado que se rende à indústria cultural e ao agendamento, as quais - ao menos aparentemente- colocavam em xeque o tratamento das pautas de cultura: 0 primeiro eixo de reflexão condiz com o trabalho do jomalista, que, muitas vezes, não toma o cuidado de se aprofundar no universo a ser reportado por ele e, consequentemente, não produz um material suficientemente claro, conciso e fácil de compreender; a segunda vertente trata dos critérios de noticiabilidade, que, ao privilegiar eventos, deixa de se posicionar quanto à identidade cultural do público que atinge (MEDINA, 1990).

Ainda nesta linha, olhando para a questão da demanda de mercado, é certo que ali reside uma outra explicação para a dicotomia cultura versus entretenimento. $\mathrm{O}$ avanço das novas tecnologias da informação - principalmente da Internet - gerou novas demandas para a produção jornalística e exigiu que antigos modelos fossem adaptados para a realidade do final do século XX e do começo do século XXI. 0 tradicional formato do jornalismo impresso, que outrora valorizava textos extensos e detalhados, perdeu seu espaço. A ordem, agora, é compilar em poucas linhas as informações necessárias para a compreensão de determinado fato, e mesmo os conteúdos críticos não dispõem de grandes espaços para serem desdobrados.

0 esclarecimento para essa transição paradigmática estáno próprio cotidiano da sociedade: por inúmeras razões, as pessoas têm trabalhado cada vez mais e, por consequência disso, diminuído 0 tempo destinado ao lazer e ao entretenimento (GORZ, 1987; DE MASI, 2000). A mídia, por sua vez, foi convidada a se reorganizar para que pudesse atender a este público que não dispõe de muito tempo, no seu dia-a-dia, para dedicar-se à leitura de jornais, revistas e similares. 0 resultado: 0 que se vê nos veículos, na última década, são textos curtos e que dão destaque a um fato e não a discussões em torno dele. Além disso, em cadernos de cultura há grande parcela do espaço destinado exclusivamente para aqueles conteúdos de entretenimento, que não promovem o senso reflexivo do leitor.

Quanto à superficialidade do conteúdo textual, esta pode ser explicada a partir de algumas pistas já encontradas por profissionais e pesquisadores. Seus principais apontamentos dizem respeito à rotina dos cadernos diários (DAVILA, 1996; PIZA, 2003), queacabam pornão seaprofundar nos assuntos estampados em suas páginas e muitas vezes sequer o contextualizam: ao que tudo indica, 0 superficial é resultado de pautas elaboradas com base em "achismos", sem opinião fundamentada, e que valorizam as celebridades e os relatos de eventos; é reflexo do pouco espaço físico para que o jornalista reflita em cima de sua abordagem (haja vista a redução do número de linhas utilizadas para cada texto); é, ainda e sobretudo, a falta de preparo dos jovens profissionais (ROD RIGUES, 2001).

Nessadiscussão háaindamuitos encontros e desencontros de ideias e de posicionamentos. E se existe um ponto em comum entre elas é o da necessidade de se conceber um jornalismo especializado em cultura muito mais fértil do que se tem atualmente (VARGAS, 2004). Contudo, ainda há que se pensar que os fatores que tornaram a produção jornalística da área muito mais pragmática do que reflexiva não podem ser pensados como um fenômeno isolado: eles acompanham, em larga escala, os acontecimentos que atingiram a própria cultura brasileira.

Seria impossível negar que o trabalho desenvolvido por veículos de cultura deixou de ser o que era no início de sua história. É mais do que latente que, hoje, a produção de "serviço" é muito maior do que de conteúdos interpretativos, críticos e questionadores. E mesmo aqueles que conseguem se manter mais para 0 lado da reflexão, o faz num espaço tímido, com destaque para fotografias, artes gráficas e outros elementos "decorativos". Nas revistas mensais, por exemplo, o espaço destinado a imagens éconsideravelmentemaior do queamancha ocupada por letras; na imprensa diária, então, apenas os cadernos de domingo - com raríssimas exceções - circulam com um maior volume de textos, dando 
margem a observações mais aprofundadas (FARO, 2006). Mas não é apenas na mídia impressa que isso ocorre: em outros suportes (rádios, TV, internet etc.), a valorização do entretenimento também pode ser vista a olhos nus, levando a crer que não há grande empenho na promoção de algo mais consistente, que pelo menos se achegue ao que se espera de um bom jornalismo cultural.

\section{0 filão das variedades}

A atenção dispensada aos conteúdos de variedades, estampados em grande proporção na imprensa brasileira, principalmente dentro dos cadernos diários de cultura, tem sido muito pequena, em vista da boa aceitação das empresas jornalísticas e do próprio público por esses conteúdos (ASSIS, 2007). A impressão que se tem é que sua definição e a demarcação dos assuntos que compõ em o rol do "jornalismo de variedades" é quase um senso comum, fato que se revela um tanto quanto contraditório quando se busca entender como tal especialidade se organiza na mídia. Isto é, não há um consenso para explicar o que seria de fato essa produção e que diferenças ela promove nas editorias tradicionais, a não ser aquilo que prediz o óbvio: são assuntos leves e descontraídos, que informam e entretém, sem necessariamentelevar a umareflexão.

$\mathrm{Na}$ linha do tempo dos estudos de mídia elaborados no Brasil, um dos primeiros registros que versam sobre este tema data da década de 1980, assinado por Mário Erbolato (1981), que enumera os assuntos, figuravam pela imprensa naquela época: crítica literária; turismo; crítica de televisão e de rádio; assuntos agrícolas; cinema; assuntos femininos (que incluem críticas de livros, economia doméstica, culinária, medicina, moda, beleza, trabalhos manuais, agenda de viagem, decoração e jardinagem); suplementos infantis; automobilismo; efemérides e rememorações; curiosidades; tempo; horóscopos; filatelia;numismática; orientações parao lazer; cinofilia; profissões e atividades; e histórias em quadrinhos.

Duas décadas depois dessas primeiras observações, muitas outras pautas passaram a ser exploradas dentro da classificação de variedades. As mais aparentes, sem dúvida, são moda, decoração, beleza e estética corporal, comportamento e gastronomia (GARCIA; MIRANDA, 2005; SILVA, 2005). Diariamente, ou em dias específicos da semana, os veículos impressos e programas de TV e derádio exploram esses temas, que chegam a disputar lado a lado com os demais assuntos de cultura, e, em alguns casos, ocupar um espaço físico bem maior. $\mathrm{E}$ 0 interesse por tais produtos não é só dos leitores. D entro das redações, essas categorias são diletas dos repórteres, por não se prenderem a critérios de noticiabilidade e oferecerem a possibilidade de trabalhar com criatividade.

Além das novas pautas trabalhadas atualmente pela imprensa, há quem chame de "variedades" as matérias sobre eventos artísticos e lançamentos. Na visão de Piza (2003), por exemplo, a diferença entre textos dessa natureza e conteúdos eruditos é facilmente percebida: os primeiros são comumente encontrados em cadernos diários, cujo discurso simples e maniqueísta os tornam um "subproduto" do jornalismo cultural; já os suplementos que circulam nos finais de semana, com textos mais extensos e reportagens mais densas, se destinam mais à erudição, embora muitas vezes também se rendam às resenhas e aos textos meramente informativos.

De qualquer maneira, não se pode negar que uma das razões de existir do jornalismo de variedades é sua função como prestador de serviços. Ao oferecer aos leitores, por exemplo, roteiros gastronômicos ou dicas de como cuidar do corpo, os jornais também exercem sua função seletiva, mostrando um leque de possibilidades para os momentos de lazer e diversão. As matérias de comportamento, então, que relatam a vida cotidiana e apontar maneiras para melhorá-la, se caracterizam como uma prática comum ao jornalismo contemporâneo, chamada denews you can use(notícias que você pode usar) (CANDIANI, 2007).

Por mais que as pautas dessa natureza sejam descontraídas, elas devem ser planejadas e executadas com objetivos bem definidos: apontar tendências, revelar novidades, tratar de aspectos intrínsecos à vida das pessoas, elaborar roteiros com dicas precisas, descrever personagens, enfim, primar por um jornalismo de variedades com qualidade, com a atuação de profissionais capacitados e com vasto conhecimento sobre temas dessa natureza.

\section{Propaganda e concorrência (e vice-versa)}

A maioriadosnoticiáriosdeculturaoferecidos pela imprensa brasileira - principalmente os que concentram esforçosnadivulgação de shows eeventos 
artísticos sem qualquer aporte crítico - provoca, no mínimo, um questionamento em seu público-leitor: trata-se de conteúdo jornalístico ou de propaganda? A delicada relação entre essas duas áreas, reflexo de um jogo de interesses comerciais e mercadológicos, dos quais dependem as redações, é um dos principais responsáveis - se não o principal - pelas críticas que põem em dúvidaa credibilidade do jornalismo cultural, uma vez que as fronteiras entre a informação e 0 merchandising parecem não existir.

Mas, por essa estrada, há pelo menos três caminhos diferentes que limitam a autonomia dos veículos: a ânsia pelo furo, a influência das assessorias de imprensa e a relação com produtores culturais (COUTO 2007; TINHORÃO, 1999). A imprensaintegraum sistema de produção capitalista, cuja estrutura depende de recursos financeiros e as visões estão sempre voltadas para a conquista do mercado e para o lucro. Notícia, nesse sentido, é produto à venda no mercado da informação (MEDINA, 1988), passível de concorrência e de disputa por um espaço e por agradar seu público, mesmo que isso renegue as ideologias da profissão jornalística, entendida como um território crítico e não como um espaço "propagandístico".

0 primeiro caminho citado, retrato da concorrência, é um pecado cometido não somente pela editoria de cultura: a corrida para dar uma notícia em primeira mão faz, na maioria das vezes, com que o produto final não tenha a qualidade que se espera deum material jornalístico, principalmente por conta da falta de tempo para uma apuração precisa e idônea (COUTO, 2007). No caso específico do jornalismo cultural, a falta é ainda mais grave, a começar pela obsessão em antecipar determinado assunto (o lançamento de um livro, a estreia de um espetáculo, a gravação de um CD etc.): por um lado, o trabalho do jornalista pode sair bem aquém do ideal - já que, na pressa, não há tempo para que ele leia a publicação, conheça o teor da apresentação, ouça a gravação... - , fazendo com que o noticiário até saia na frente, mas sem qualidade; na outra ponta, o problema está da superantecipação do fato, ou seja, se algum dos eventos descritos for divulgado com uma antecedência muito grande, corre-se o risco do público esquecer, ou, então, obriga o jornal arepetira mesmainformação diversas vezes (STRECKER; VENTURA, 1989).

O segundo item da lista aponta para um fenômeno relativamente recente: a participação dos assessores de imprensa na definição e elaboração das pautas trabalhadas pela mídia. D epois que jornalistas ocuparam totalmente as assessorias - antes conduzidas por profissionais de Relações Públicas , o contato com as redações e a interferência em sua produção se tornou mais evidente, em razão a própria compreensão que os primeiros profissionais mencionados possuem sobre a rotina dos meios de comunicação (CO STA, 2003). Além disso, o material produzido dentro das assessorias (releases -ou pressreleases) virou uma "mão naroda" para os profissionais que estão do outro lado, que já recebem boa parte das informações prontas, faltando apenas entrevistar as fontes para recolher informações complementares. No entanto, há de se observar que o que diferencia a prática do jornalismo cultural dos demaiséafacilidade de previsão e de planejamento para um determinado acontecimento, diferente da produção de notícias hard, que depende de um fato já ocorrido para se organizar(STRECKER;VENTURA, 1989). D eduzse, portanto, que a situação, para o jornalista cultural, é propícia para uma apuração bem elaborada e evita que ele se prenda apenas às informações de um release, até porque o material elaborado por assessores de imprensa nada mais objetiva do que "vender" uma boa imagem de seus clientes (pessoais ou institucionais) e dos produtos ou eventos que eles tenham a oferecer (tal como o texto publicitário, que tem como finalidadevenderalgo);jáo texto jornalístico pode ser redigido com liberdade para dar pistas de reflexão ao seu leitor em potencial, e não, simplesmente, ser uma reprodução de materiais previamente preparados.

A terceira curva dessa estrada comprometedora esbarra no relacionamento dos jornalistas com os produtores culturais. No Brasil, é comum que o jornalista que escreve uma reportagem sobre um produto e/ ou um espetáculo também faça a crítica sobre o mesmo assunto. Mas, na posição de repórter, o profissional dependedo produtor cultural para agendar entrevistas, para conhecer o material que ira divulgar e até mesmo para ter acesso a quem, de fato, tem autoridade para se manifestar sobre determinado tema. Além do mais, ao ocupar seu lugar como crítico, ele terá de apontar os erros e os acertos da mesma produção, o que nem sempre costumaagradaràquelesqueafizeram. D esse ponto, surgem dois problemas: primeiro, se a entrevista for concedida antes, corre-se o risco de o jornalista se deixar deslumbrar pelo entrevistado e acabar deslizando seus comentários a favor de tal personalidade, mesmo que tenha consciência de 
que sua obra não é excelente; contudo, se as críticas forem feitas antes da divulgação jornalística, visando a uma postura imparcial, o jornalista pode comprometer sua relação com os produtores e ser tratado até mesmo com desconfiança (COUTO, 2007). Sem sombra de dúvidas, o ideal é que cada uma das funções seja exercida por um profissional diferente.

Ainda sobre o marketing cultural, existe uma linha de raciocínio que mostra como as coações mercadológicas geram estresse na esfera do jornalismo, por conta da influência que exercem sobre a mídia. $\mathrm{O}$ grande problema é que essa pauta de discussão, além de séria, não apresenta saídas aparentes; ao contrário, percebe-se que apenas poucos profissionais encontram formas de fugir das informações geradas e impostas pela indústria cultural (MEDINA, 2007).

Uma outra "praga" queassola o jornalismo cultural, como define o jornalista Daniel Piza (2003), é o famigerado "jabá" (ou propina), que se subdivide em dois tipos. Em primeiro lugar, está 0 considerado "ilegal", que seria o pagamento direto para a divulgação e veiculação de um produto seja, por exemplo, na forma de textos jornalísticos que falem bem de uma obra ou de rádios que toquem uma determinada música repetidas vezes. Em seguida, a prática da doação de "presentinhos" - objetos, passeios, viagens, cortesias etc. - , que não chega a ser ilegal, mas que deve ser evitada pelosjornalistas decultura, atémesmo por questões éticas e pelo risco que se corre de colocar a prática profissional em risco, uma vez que sempre que um material jornalístico é evidentemente visto como publicitário, este certamente é repudiado e apontado como algo de pouca (ou nenhuma) credibilidade (PIZA, 2003; CHAPARRO, 2007).

Além disso, uma enorme gama de produtos culturais é oferecida num curto espaço de tempo, provocando uma dificuldade na hora de escolher o que deve ser publicado. E como a maioria desses produtos é encaminhadaàs redações acompanhadas de material de divulgação fotografias e todas as informações necessárias para a construção de um texto - , os filtros pouco separam o que é bom do que é ruim e, por fim, publica-se o que é mais fácil de produzir. Por outro lado, também não se pode esquecer que o problema da submissão dos veículos de comunicação brasileiros às produtoras de cultura se deve, em partes, à própria estrutura dos cadernos de cultura: ao que tudo indica, o Brasil é o país onde se oferece o maior espaço para conteúdos culturais na imprensa diária, realidade que até poderia ser encarada como positiva. No entanto, o espaço em demasia acaba se tornando um problema, já que é preciso conhecê-lo de alguma forma; o conteúdo jornalístico, por fim, acaba "contaminado" pela publicidade (STYCER, 2007).

Todo esse achego à propaganda, ocasionado em diversas frentes, recebeu de estudiosos do assunto uma sugestiva nomenclatura: jornalismo cor-de-rosa. A definição de Leandro Marshall (2003, p. 17), na verdade, assinala a função mercadológica da notícia, que a torna um produto "marketizado, mercantilizado, estetizado e essencialmente light, um amálgama estético e capitalista, um instrumento-meio dos objetivos diretos ou indiretos do sistema edalógicaultraliberal". Em outras palavras, é uma fusão entre jornalismo e propaganda, especialmente encontrada nas páginas culturais, que muitas e muitas vezes preenchem com conteúdo jornalístico apenas o espaço que não foi ocupado por material publicitário. Em alguns casos, ainda, tanto o texto quanto o anúncio abordam 0 mesmo assunto, transformando o todo em uma grande mercadoria, cujas fronteiras entreinformação e persuasão sequer podem ser notadas.

\section{A crítica e o crítico}

A crítica é, numa tradução minimalista das ideias de Marcelo Coelho (2000), uma das mais nobres responsabilidades exercidas pelo jornalismo cultural. Isso porque não é fácil delimitar uma linha tênue entre opiniões fundamentadas e julgamentos pessoais, principalmente nos dias de hoje, quando não se encontram tantos espaços para tal exercício, comparando-os às numerosas linhas ocupadas, no passado, por folhetins e rodapés. Além disso, na maioria das vezes, as críticas culturais nada mais são do queresumos/ sinopses deprodutos oferecidos no mercado das artes, elaboradas com pouco embasamento para elogiar ou para apontar falhas.

Por esses motivos, há tantas queixas a respeito dostrabalhosdessanatureza, desempenhados pela imprensa brasileira: lamenta-se que - salvo alguns ícones consagrados no assunto - quase não existam mais críticos competentes e seguros daquilo que escrevem. A própria relação entre textos informativosecríticosa respeito das "vacas sagradas", 
denominação que D aniel Piza (2003) dá aos artistas que têm passe livre pela mídia, faz com que os veículos impressos destinem um considerável espaço para falar sobre um lançamento e, logo em seguida, imprimam um texto classificando o mesmo produto como algo não tão bom.

É mais do que perceptível que a relação do crítico com os leitores nunca foi das melhores. Boa parcela do público vê as opiniões sobre determinado assunto como algo sem importância, cujo teor apenas reflete a empatia ou a antipatia de quem as escreveu. Mas esse debate, além de polêmico, quase não aponta para conclusões. Se 0 crítico vai contra as opiniões dos leitores, é taxado como alguém que faz péssimas recomendações ou rejeita o que diverte; se opta, entretanto, pela unanimidade, mostra que sua intenção é agradar a um gosto médio (SANTO S, 1997; PRIG O L, 1998).

Pormais subjetivo que o trabalho do crítico possa parecer, ele precisa se distanciar o máximo possível de seus interesses pessoais, muito embora todo juízo de valor reflita o repertório e a visão de mundo de quem o emite. 0 requisito básico para ser um bom crítico e, consequentemente, desenvolver críticas coerentes é gostar do seu objeto de análise, conhecê-lo, saber de seu passado e ter noção do futuro que o espera. Portanto, sua boa atuação depende, necessariamente, de seus conhecimentos a respeito daquilo que se propõe a avaliar.

Indiscutivelmente, o papel do crítico, dentro do jornalismo cultural, está em acompanhar as mobilizações provocadasporobras dearte,espetáculos e livros (AGUIAR, 2000). E por tratar-se de um trabalho autoral, também há que se levar em consideração quea credibilidadedacrítica corresponde, particularmente, ao crédito conquistado pelo próprio crítico, tendo sua imagem quase sempre associada ao teor dos valores atribuídos a produções diversas.

\section{Preparo profissional}

O preparo do jornalista é assunto que também resulta em grandes discussões, principalmente porque a qualidade do jornalismo cultural praticado pela imprensa nada mais é do que fruto das competências desse profissional. Presumese que, ao cruzar os portões que separam a universidade do mercado, talindivíduo tenhabagagem suficiente para pôr seu ofício em prática, tanto com habilidades técnicas quanto com repertório de conhecimento. Mas a realidade não é bem assim. As universidades, por mais que procurem aperfeiçoar seus cursos e até ofereçam conteúdos além da grade curricular, não dão conta de especializar o aluno em uma área, em apenas quatro anos, tendo ele que cumprir com uma série de outras obrigações acadêmicas (TEIXEIRA COELHO, 2007). Até porque, do jornalista que atua na área aqui abordada, exige-se muito mais do que o domínio das técnicas jornalísticas: para que desenvolva um trabalho exemplar, cabea ele o conhecimento eacompreensão das artes e dos fenômenos culturais. Urge, portanto, repensar a formação dos novos profissionais para, consequentemente, propor a revisão da qualidade do trabalho realizado dentro das redações, a fim de que seja produzido um "bom jornalismo cultural" (VARGAS, 2004).

A o observaro comportamento dejornalistas no exercício da profissão, em especial daqueles que escrevem sobre cultura, constata-se que apenas um curso de graduação não é suficiente para imbuir uma pessoa de todo o conhecimento que se espera que ela tenha. A expectativa é que um repórter de cadernos e revistas dessa natureza tenha uma visão completa do assunto que irá trabalhar. Um exemplo: para escrever sobre a estreia de um novo filme espanhol, ele deve (ou, pelo menos, deveria) conhecer os clássicos do cinema hispânico, todas as obras do diretor em questão e as demais produções contemporâneas; e o mesmo acontece com outros temas. Somente assim, tendo um sólido conhecimento daquilo que já foi feito e do que está em voga atualmente, é que se podem estabelecer comparações, dar opiniões consistentes, fazer críticas embasadas e, acima de tudo, fazer um trabalho bem feito. Caso contrário corre-se o risco de encher os diagramas dos jornais com textos "vazios".

Sem entrar no mérito da obrigatoriedade do diploma de jornalismo para o exercício da profissão, cuja exigência ainda repercute impasses, há um acordo entre quase a totalidade dos profissionais da imprensa que um curso superior é sempre um espaço para o aprimoramento profissional. 0 que tem sido discutido, no entanto, é que apenas uma faculdade - especificamente a de Jornalismo - não é suficiente para formar um profissional especializado em cultura, o qual não deve se posicionar no quadro que se intitula "gente improvisada" (TEIXEIRA COELHO, 2007). A pós-graduação ajuda a preencher um pedaço dessa lacuna deixada pela graduação, mas também não 
basta. A busca pela excelência, ao que parece, é uma tarefa que precisa ser renovada de tempos em tempos, atrelada ao desenvolvimento do próprio indivíduo (DAPIEVE, 2002).

Por tratar-se de uma ramificação específica da área, o jornalismo cultural necessita que sua produção fique aos cuidados de recursos humanos especialmente qualificados, principalmente por conta da subjetividade dos assuntos abordados. Afinal, como pode um repórter elaborarumareportagem consistente so bre o patrimônio cultural de determinada localidade se nada souber sobre isso? Na verdade, não poderá (DAPIEVE , 2002; PIG NATARI, 1996). É preciso ter autonomia para elaborar bons textos, é preciso ter competência, principalmente porque existe uma grande diferença entre 0 que se entende por e o que realmente é o jornalista cultural. E 0 acúmulo de saber é o que dirá em qual das duas categorias o profissional poderá se encaixar.

Se o jornalista não estiver suficientemente preparado para atuar na editoria de cultura, seu trabalho se resumirá naquilo que se denomina "fãclubismo" de textos (VALE, 2007). Isto é, por não ter bagagem necessária para debater os temas por ele abordados, certamente irá se render à bajulação. Ademais, também não terá criatividade para elaborar/ sugerir pautas interessantes e se prenderá ao calendário deeventos ou dedatas comemorativas, repetindo exaustivamente 0 que já foi feito no ano anterior, no antecedente e assim por diante (VARGAS, 2004). E não é isso que se deseja. Almeja-se que o jornalista estabeleça critérios para a avaliação do que é "bom" ou "ruim" em termos de arte e cultura; faça entrevistas consistentes e retire do entrevistado informações relevantes, diversificadas - e não aquilo que todo mundo já sabe -; tenha coragem de ir contra o público, mesmo que este prefira atrações sem qualidade (PIZA, 2003; RODRIGUES, 2001).

\section{CONSIDERAÇÕES FINAIS}

A qualidade do jornalismo cultural brasileiro, questão-chave desta reflexão, vem sendo amplamente discutida por acadêmicos e por profissionais do mercado, tendo sido o teor dessas preocupações devidamente registrado em livros e periódicos. Trata-se, evidentemente, de uma percepção coletiva a respeito do que realmente interessa ao jornalismo: ter consistência e atender às expectativas do público-leitor das editorias decultura.

Reunindo publicações essenciais para 0 aprofundamento na temática proposta, este artigo apresentou cinco caminhos para uma discussão acerca dos rumos da produção jornalística na área cultural, sem ter tido a pretensão de esgotar tais eixos. Ao contrário, procurou, como mencionado acima, conduzir todas essas vias a um lugar chamado "compromisso com o bom jornalismo".

Embora enfrente uma série de problemas, os quais nem sempre têm encontrado esforços para serem sanados, o jornalismo cultural ainda tem um forte peso na imprensa brasileira. Sua morte ainda não foi anunciada (e, certamente, não será proclamada tão cedo). Mas é necessário que suas condições de produção e de recepção sejam constantemente repensadas.

\section{REFERENCIAS}

AGUIAR, F. As questões da crítica literária. In: MARTINS, M. H. (Org.). O utras leituras: literatura, televisão, jornalismo e artes e cultura, linguagens interativas. São Paulo: SENAC/ Itaú Cultural, 2000. p. 37-54.

ASSIS, F. Concepção e produção do jornalismo de variedades na mídia impressa: um estudo do caderno Valeviver. Em Questão, v. 13, n. 1, p. 57-71, 2007.

CANCLINI, N. G. Diferentes, desiguais e desconectados. Rio de Janeiro: Ed. da UFRJ, 2006.

CANDIANI, H. R. A publicidade sem

fronteiras. Observatório da Imprensa. Disponível em: <http:/ / observatorio.ultimosegundo.ig.com.br/ artigos/ jd20052000.htm>. Acesso em: 04 mar. 2007.

CHAPARRO, M. C. Bumerangues e propaganda. Instituto Gutenberg. Boletim, n. 21, série eletrônica, 1998. D isponível em: <http:/ / www.igutenberg.org/ chapa21.html>. Acesso em: 15 maio. 2007.

COELHO, M. Jornalismo e crítica. In: MARTINS, M. H. (O rg.). Rumos da crítica. São Paulo: SENAC/ Itaú Cultural, 2000. p. 83-94. 
CO STA, L. M. P. O jornalismo a quatro mãos: repensando a responsabilidade social. In: (O rg.). X da questão: jornalistas de redação e de assessoria de imprensa. Taubaté, SP: Papel Brasil, 2003. p. 11-23.

COUTO, J. G. Jornalismo cultural em crise. In: DINES, A.; MALIN, M. Jornalismo brasileiro: no caminho das transformações. Brasília: Banco do Brasil, 1996. p. 129-131.

Jornalismo cultural e propaganda. Observatório da Imprensa. D isponível em: <http:/ / observatorio.ultimosegundo.ig.com.br/ mat2002b.htm>. Acesso em: 05 jun. 2007.

DAPIEVE, A. Jornalismo cultural. In: CALDAS, A. (O rg.). Deu no jornal: 0 jornalismo impresso na era da Internet. São Paulo: Loyola, 2002. p. 94-112.

DÁVILA, S. Leitores, torcedores e jornalistas. Folha de S.Paulo, São Paulo, 04 set. 1996. Caderno Ilustrada, p. 6.

DE MASI, D. 0 futuro do trabalho: fadiga e ócio na sociedade pós-industrial. Rio de Janeiro: UNB/ José Olympio, 2000.

ERBO LATO, M. L. Jornalismo especializado: emissão de textos no jornalismo impresso. São Paulo: Atlas, 1981.

FARO, J. S. Nem tudo que reluz é ouro: contribuição para uma reflexão teórica sobre 0 jornalismo cultural. Comunicação \& Sociedade, v. 27, n. 45, p. 143-163, 2006.

GARCIA, C.; MiRANDA, A. P. Moda é comunicação: experiências, memórias e vínculos. São Paulo: Anhembi Morumbi, 2005.

GORZ, A. Adeus ao proletariado: para além do socialismo. Rio de Janeiro: Forense Universitária, 1987.

MARQUES DE MELO, J. Indústria cultural, jornalismo, jornalistas. Intercom: Revista Brasileira de Comunicação, ano 14, n. 65, p. 20-29, 1991.

MARSHALL, L. 0 jornalismo na era da publicidade. São Paulo: Summus, 2003.

MED INA, C. Leitura crítica. In: LIND O SO, F. (O rg.). Rumos [do] Jornalismo Cultural. São Paulo: Summus/ Itaú Cultural, 2007. p. 32-35.
É preciso se contaminar de arte. Ensaio, ano 1, n. 2, p. 9-13, 1992.

Jornalismo e a epistemologia da complexidade. Comunicação \& Política, ano 9, n. 11, p. 85-93, abr./ jun. 1990.

. Notícia, um produto à venda: jornatismo na sociedade urbana e industrial. São Paulo: Summus, 1988.

NUNES, M. F. R. Cultura também é notícia: jornalismo cultural no impresso e na TV. 2003. 109 f. D issertação (Mestrado em Comunicação Social) - Universidade Metodista de São Paulo, São Bernardo do Campo, 2003.

PIGNATARI, D. A Escala Richter da cultura. In: D INES, A.; MALIN, M. Jornalismo brasileiro: no caminho das transformações. Brasília: Banco do Brasil, 1996. p. 132-154.

PIZA, D. Jornalismo cultural. São Paulo: Contexto, 2003.

PRIG O L, V. Notas de jornalismo cultural: um estudo sobre resenhas de livros em seis cadernos semanais de cultura. 1998. $114 \mathrm{f}$. D issertação (Mestrado em Comunicação Social) - Universidade Metodista de São Paulo, São Bernardo do Campo, 1998.

ROD RIG UES, S. Tendências contemporâneas do jornalismo cultural. In: DINES, A. (Org.). Espaços na mídia: história, cultura e esporte. Brasilia: Banco do Brasil, 2001. p. 12-17.

SANTOS, M. V. Leitores criticam a crítica. Folha de S.Paulo, São Paulo, 03 ago. 1997. Brasil, Caderno Ilustrada. p. 6.

SILVA, P. R. A ação dos jornalistas na noticiabilidade de reportagens de comportamento: a gênese das pautas no suplemento temático Meu Filho, do jornal Zero Hora. In: CONGRESSO BRASILEIRO DE CIENCIAS DA COMUNICAÇ̃̃ O, 28., 2005, Rio de Janeiro. Anais eletrônicos... São Paulo/Rio de Janeiro: Intercom/ UERJ, 2005.

STRECKER M.; VENTURA, Z. Cadernos culturais. In: RITO, L.; ARAÚJO, M. E.; ALMEIDA, C. J. M. (O rg.). Imprensa ao vivo. Rio de Janeiro: Rocco, 1989. p. 93-108.

STYCER, M. Seis problemas. In: LIND O SO, F. (O rg.). Rumos [do] jornalismo cultural. São Paulo: Summus/ Itaú Cultural, 2007. p. 90-98. 
TEIXEIRA COELHO, J. O utros olhares. In: LIND O SO, F. (O rg.). Rumos [do] jornalismo cultural. São Paulo: Summus/ Itaú Cultural, 2007. p. $17-25$.

TINHO RÃ O, J. R. Mitos do jornalismo cultural. Anuário Cásper Líbero, n. 1, p. 4750, 1999.

VALE, I. Jornalismo cultural: reflexões. Digestivo Cultural. 2005. Disponível em: <http:// www.digestivo cultural.co m/ en saios/ ensaio.asp?codigo=132>. A cesso em: 18 jul. 2007.

VARGAS, H. Reflexões sobre o jornalismo cultural contemporâneo. Estudos de Jornalismo e Relações Públicas, v. 4, n. 4, p. 17-25, 2004.

Recebido: 18/ 05/ 2008

Received: 05/ 18/ 2008

A provado: 22/ 09/ 2008

A pproved: 09/22/ 2008 